\title{
Drug abuse among street children (Case study: Commercial vans casual apprentices at car parks)
}

\author{
Yahya Muhammed Bah ${ }^{* 1}$ \\ ${ }^{1}$ University of The Gambia, School of Arts and Sciences, Brikama Campus, The \\ Gambia, West Africa \\ *)Corresponding author, ఏe-mail: yahyamuhammed@yahoo.co.uk
}

\begin{abstract}
In the Gambia like all nations, drug abuse is seen as a social and health problem that has many serious implications for the physical, social, psychological and intellectual development of the victims more especially, the children. Though there some studies on drug abuse, there is none on children and drug abuse focusing on the street children the most vulnerable category. Street children are hypothesized to be more at risk of any epidemic, including drug abuse. This study sought to determine the risk and prevalence of drug abuse among street children focusing on those in the car parks. The research was focused on six critical areas: level of knowledge of drug abuse, perception towards it, level of knowledge of the causes of it in the community and among street children, level of knowledge of negative impacts of it, level of knowledge of the preventive methods; and level of knowledge of the support services and treatments needed by victims. A structured questionnaire was used to collect the data from thirty five participants were interviewed. The data was presented and analysed using tables and percentage. The findings revealed among other things, that there is high level of awareness of drug abuse, but the feeling towards it is mixed.
\end{abstract}

Keywords: Drugs, abuse, street children, casual van apprentice; and commercial van driver.

How to Cite: Bah, Y.M. (2019). Drug abuse among street children. COUNS-EDU: The International Journal of Counseling and Education, 4(1), 1-14. DOI: https://dx.doi.org/10.23916/0020190416610

\section{Introduction}

Drug abuse is not loner just part of the seedy underbelly of society as it has exploded into the open streets, reaching nearly every corner of civilization. The once silent killer is claiming more victims than ever before, and in horrific manners. Sadly, drug abuse continues to maintain a stranglehold on adolescences stripping away their chances for stable, happy and productive life, The Real Truth (n.d.). The history of drug abuse is as old as mankind. Human beings have always had a desire to eat or drink substance that make them feel relaxed, stimulated or euphoric. The discovery of fermentation and farming since $6000 \mathrm{BC}$ is when people started to use drugs. The first drug to be abused was homemade alcohol wine and the level could read up to $14-16 \%$. It was used in religious rites and children were given it too in their Holly Communion. Other drugs were used for legitimate purposes, medical or scientific purposes, (14) Matowo, A. S. (2013). Essentially, drug abuse started to be high through various experimentations and 


\section{COUNS-EDU}

Vol.4, No.1, 2019

people diverted the use of drugs for money generating activities. However, recognizing the effects was noted and restriction to abuse legalized but the problem still goes high.

While In 2015 about a quarter of a billion people used drugs, United Nations Office on Drugs and Crime (UNODC) (n.d.). In 2016, according to UN 250 million people between the ages of 15 and 64 used at least one drug in 2014 and more than 29 million are suffering drug use disorders compared with 27 million in 2013. Of the 12 million people who inject drugs $14 \%$ are now living with HIV. Heroin top the list of the killing drug and the poorest societies bear the brunt, UN News (2016).

Africa now occupies second position worldwide in the trafficking and consumption of illegal drugs. The UN estimate in 2014, there were 28 million drug users in Africa and 37,000 people die annually from diseases associated with the consumption of illegal drugs. The children are identified as the most vulnerable, especially those who cannot resist peer pressure, DW Made for Mind (2013). Therefore, it seems drug addiction has reached epidemic levels across the world and the spectrum of the drug on the drug market has widened considerably, becoming one of the social problems that affect everyone, everywhere, either directly or indirectly and children are no exception, Mabeyo, (2010) as cited in Matowo, A. S. (2013). Children are a valuable asset and pride, not only to their family but to the nation. Similarly, today's children are tomorrow's adults and builders of the nations and deserves all protection form the menace (91) Singh, B. et al., (2017). Therefore, the use of substances among adolescents is not only a public health concern but equally socio-economic one. The prevalence among the youth is alarming. Globally, in 2011, about 211,000 deaths were recorded, Somani, S. et al., (2016). In view of the fact that adolescence is a critical stage in the life and is considered the most transformative period, it is incumbent upon all to fight the menace.

The Gambia like all developing countries has many problems one of which is substance abuse and associated problems. Through 2001, increased in the abuse of cannabis, heroin, cocaine, ecstasy and other stimulant drugs were noted in the country, United Nations (2003) as cited in Anderson, Z. (2004). Risk factors for drug abuse represent challenges to individual's emotional, social and academic development. These factors can produce different effects depending on the individual's personality traits, phase of development, and environment, National Institute on Drugs (2003). Abuse of solvent/inhalants amongst children in The Gambia have been around for some years and is estimated that more than $40 \%$ of illicit drugs users are under the age of 20 years to escape problems such as poverty, failure in school and unemployment (State house, 2003; United Nations, 2003; International Youth Parliament, 2004) as cited in Anderson, Z. (2004).

Because children are the source of hope and inspiration for the society, they have the right to be protected, supported and brought up in a positive environment. Unfortunately, children do not only live in poverty but tens of millions of them around the world find themselves living or working in the streets as street children. Street children is a growing global phenomenon that is characterized by vulnerable children migrating to the streets in the urban areas in developed and developing countries (Niekerk, V. 2007) as cited in Molahlehi, L. A. (2014).

However, research shows that the street children phenomenon is not a new socio-economic problem as for a long time, vulnerable children whose personal and ecological resilience resources were depleted have adopted streetism in order to fend for themselves or supplement family income, De Moura, (2005) as quoted in Molahlehi, L. A. (2014). Despite some evidences existing, it is difficult to know how many children live and work on the streets, since they are a mobile group who occasionally enter and exit the category. Therefore, their mobility is one of the main reasons why their number cannot be confirmed with sufficiently, Malindi, (2009) as cited in Molahlehi, L. A. (2014). Their being sometimes persecuted by the police for being in the street, search for greener pastures, and bullying that occurs among them also adds to their constant mobility, Molahlehi, L. A. (2014).

Although the number of street children is unknown, existing estimates suggest that tens of millions of children are street-based and that their numbers are rising secondary to global population growth, the HIV epidemic, migration, and increasing urbanization, UNICEF. The state of the world's children, (2012) as quoted in Woan, J. et al., (2013). Therefore, street children constitute a marginalized population in most urban centers of the world. In their marginalized state they constitute a truly 'hidden' population in which they are not covered nor can they be found in the national census, education or health data, largely because they have no fixed address. 
Street children are often found in busy places such as railway stations, bus stations, in front of film or night clubs, with no adult supervision, sleeping in half-destroyed houses, abandoned basements, under bridges and in open air, UNICEF. Street and unsupervised children of Africa, (2003) as cited in Cumber, S. M., et al., (2015). To survive they have been seen to roam the streets of urban areas begging and looking for jobs in order to obtain food and other basic necessities. They usual work in poor conditions, dangerous to their health, and starve some days.

Therefore, street children survive on the streets through conventional and unconventional ways such as rubbish picking, shoe shining, flower selling, petty crimes, drug abuse, begging, panhandling, prostitution, petty theft; and drug trafficking. They also develop passive and aggressive attitudes, replacing their families with street gangs and experiencing social, sexual, physical and emotional abuse, Grundling, et al., (2004) as quoted in Molahlehi, L. A. (2014). Therefore, streets throughout the world are home to millions of children who endure hardships and injustices while struggling to survive, Embleton, L. et al., (2013). Often, these children lack a balanced social network, and do not have an adequate relationship with an adult caregiver, leaving them extremely vulnerable with many of their physical, mental, and social needs unfulfilled, Towe, V. L. et al., (2009) as cited in Embleton, L. et al., (2013). Thus, Street children are face with a myriad of challenges in their daily lives, including child abuse and exploitation, Bal, B. et al., (2010) as quoted in Embleton, L. et al., (2013). Under such circumstances, they fall into patterns of drug abuse in order to cope with their adverse conditions and survive on the streets, Towe, V. L. et al., (2009) as quoted in Embleton, L. et al., (2013). This, has warranted the global concern for the plight of street children growing over the years, and as such governments and community organizations have attempted to design interventions in order to ameliorate their plights.

The Gambia government as a party to many international and regional conventions: Convention on the Psychotropic Substance of 1971, UN Convention Against Illicit Traffic in Narcotic and Drugs and Psychotropic Substances of 1988, in response to the concerns, has developed numerous policies (e.g. National Drug Policy) and laws (e.g. National Drug Control Act) to tackle it and its associated problems. All major drugs like cannabis, heroin and cocaine are illegal in the country and it is illegal to sell alcohol to under than 16 years, Anderson, Z. (2004). Furthermore, to strengthen the fight against drugs the government has established the National Drug Control Council (NDCC) to be the national drug law enforcement agency in collaboration with the National Drugs Squad (NDS), Anderson, Z. (2004). Along with the government legislations and substance use programmes, several Non-governmental organizations (NGOs) provide prevention, education and treatment for substance use in the country, Anderson, Z. (2004). However, cannabis grows naturally in the country with around three harvests per year, Anderson, Z. (2004). Despite few studies reporting prevalence there are no pooled data on the types of substance abused, reasons for abuse by children including the street children. Therefore, there is an urgent need to compile objective information about street children and drug abuse to both understand the magnitude of the problem and design programmes for prevention and rehabilitation.

\section{Method}

The study was conducted in five car parks with urban areas namely; Serekunda, Coastal road, Bundung, Banjul; and Brikama car park. The research sample was 35 people, taken using a purposive sampling technique. The data was collected by conducting individual interviews using a structured questionnaire with thirty five participants. The data analysis process was in two folds: the first fold was coding and creation of tables, preparation of variables by combining a number of codes, converting codes into variables or developing completely new variables. This was used to provide a summary of patterns that emerged from the responses.

\section{Results and Discussions}

\section{Level of Knowledge of Drug Abuse}

The results indicate a high level of awareness of drugs in the community since all the participants have not only heard of them but have personally seen them and are well familiar with the different varieties available in the community and above all have seen people abusing them. With such degree of 


\section{COUNS-EDU}

Vol.4, No.1, 2019

awareness, it is highly anticipated that the participants will do all it takes to avoid being engaged in abusing them despite being young, although age is found to be a strong risk factor. Rambaree, K. et al., (2017), the strongest predictor of reporting drug use was age. Somani, S. et al., (2016), predisposing factors for substance abuse among adolescents are age, gender, family structure and relations, poverty, availability; and accessibility of drugs. Whitesell, M. et al. (2013), adolescents are particularly susceptible to involvement in substance abuse due to the underdeveloped state of their brains, which can lead to reduced decision making ability and increased long term effects of drugs and alcohol. Alhyas, L. et al., (2015), many factors increased the risk of substance among adolescents such as peer pressure, inadequate knowledge of the harmful consequences of it, family related factors( e.g. low monitoring and pooradolescents relationship), affordability and availability. Alhyas, L. et al., (2015), inadequate knowledge of the health hazards associated with the use of substance could contribute to young people's substance abuse. Alhyas, L. et al., (2015), lack of awareness of the risk associated with alcohol and drugs trigger experimentation or abuse of drugs. Chie, Q.T. et al., (2015), participation in awareness raising project was associated with a decrease in willingness to experiment with drugs, even though all groups showed strong negative attitudes towards drug use.

Heckman, C.J. et al., (2012), inclusion of drug education in school curricula shown to be effective in modifying substance abuse related attitudes and behaviors. If the power of classroom were systematically harnessed to disseminate lessons learned from research, effective prevention strategies would have been widespread and major impacts registered. Buhler, A. et al., (2008), increasing knowledge about life skills (communication, problem solving) was followed by a more distant attitude toward tobacco and alcohol and fewer cases of nicotine.

However, the degree of knowledge and awareness of a particular phenomenon does not automatically guarantee people completely avoiding it or a behavioral change. Birch et al., (1998) as cited in Gossop, M. et al., (2001) about two-third of recently qualified doctors exceeded recommended safe drinking limits and were drinking at hazardous level. A quarter were using cannabis and 10\% were using hallucinogens, and as many as one doctor in fifteen may be affected by drug or alcohol dependence problems at some point during their careers. Majelantle, R. G. et al. (2014), increased in knowledge about the disease is not a predictor for behavioral change, although knowledge about the disease is prerequisite for change. Njord, et al., (2010) as cited in Embleton, L. et al., (2012), street children have a moderate degree of awareness about the negative health outcomes associated with drugs use, yet they continued to use inhalants.

Furthermore, the findings revealed that in the community children as young as nine years are abusing drugs. This concurs with the age of initiation of substance abuse using non-drugs like glue was 9 years old, Ramlagan, S. et al., (2010). Many adolescents started smoking, alcohol or drug use at the age 11 and younger, they have access to substances at home, from friends, or from shop or street vendors, UNICEF. Global School-Based Student Health Survey Report, Tajikistan (n.d.) as quoted in Somani, S. et al., (2016). The age of initiation was between 10 and 13 for street children who commonly use and abuse substance like alcohol, cigarettes, inhalants, cocaine, marijuana, heroin, shoemakers glue, correction fluid, paint thinner; and coca paste (Nada, K.H. et al., 2010; Hillis, S.D. et al., 2011; Elkoussi, A. et al., 2011) as quoted in Cumber, S. M., et al., (2015). Young persons have experimented with inhalants at least once by the time they are in eight grade and mean age of first time inhalant abuse is 13 years, McGarvey, E.L. et al., (1999) as quoted in Mondal, N. K. (2013). Sampasa-Kanyinga, H. et al. (2018), some students reported having tried cannabis for the first time as early elementary school.

Similarly, the results revealed that marijuana, alcohol, opium, cocaine, inhalant, and antibiotics are one of the most commonly abused drugs in the community, concurring with cannabis remains the most common illegal drug in African countries, United Nations (2003) as cited in Anderson, Z. (2004). Cannabis is both the most abuse drug and the primary illicit substance at admission to South African drug treatment centers, Peltzer, K. et al., (2010). The most common and available drugs of abuse is still cannabis, which is known to be a contributing factor to the occurrence of a schizophrenic-like psychosis, Rhodes, T. et al., (1998) as cited in Sereta, B. N. et al., (2016). The most commonly used and abused substances are cigarettes, cannabis, alcohol, inhalants, heroin and cocaine, (Antwi, J. D., Adjei, S., Asare, J. B., \& Twene, R., 2003). 
In the same vein, the findings revealed that the common abuse of these drugs was largely due to quick "highness" or drunkenness, making one work hard and long, easy accessibility and affordability, long term drunkenness, drunkenness being not easily noticed, etc. which dovetails with drugs make individual strong to do hard work, boost appetite to eat, to study to pass examinations, overcome problems, confidence to rape girls, work more to generate income for the family, provide protection for the family due to being feared by others, Ministry of Health/Ghana Health Service World Health Organization Ghana, (2003). Access to alcohol and other drugs is positively associated with their abuse Brook et al., (2005) as cited in Morojele, N. et al. (n.d.). Many adolescents started smoking or alcohol or drug use at the age of 11 and younger, because they have access to substance at home, from friends, or from shops or street vendors. Accessibility to alcohol at home and parents drinking are risk factors for the onset of alcohol use in adolescence, UNICEF. Global School-Based Student Health Survey Report, Tajikistan (n.d.) cited in Somani, S. et al., (2016). Bailey et al., (1992) as cited in Patrick, M. E. et al., (2011), ever getting high (i.e. stoned) was associated with continued use of marijuana. Parry (2004) as cited in Anderson, Z. (2004), increase development leads to better technology like refrigeration which may lead to increase heavy drinking in areas where it was not often seen before because previously alcohol beverages did not last long in very warm climates.

\section{Perception towards Drug Abuse}

The results indicate a mix feelings towards drugs abuse with very bad, bad and normal at the top which is very encouraging and at the same time discouraging in the fight and total elimination of the menace in the society especially among the children the very last hope of all families, communities and nations. Regarding the phenomenon as evil in the society occurs with the public possess a negative attitude towards dependents, Low, W. et al., (1995). Attitudes towards drug addicts or who use it were largely negative and unsympathetic, and were characterized by fear and a desire to avoid such individuals, Bryan, A. et al., (2000). Illicit drug use is a classic example of social deviance, and most of the available literature suggest that those engaged in such brand of social deviance are perceived in a negative light by society at large, Young (1987) as quoted in Bryan, A. et al., (2000). The stigma associated with substance use in South Africa is high and not necessarily dependent on the drug choice. However, a range of factors, including gender of substance user, and ethnicity of rater, may impact on stigma, Sorsdah, K. et al., (2012).

Equally, viewing the phenomenon as normal in the society in light of the unprecedented developments taking place nearly everywhere concurs with adolescents' involvement in drug abuse and selling of drugs routinely is regarded as natural, Faria, F. E.A. et al., (2015). Substance initiation is viewed as a normal adolescent behavior that is expected to produce pleasurable physical and psychoactive effects, Kingston, S. et al., (2017). Majority of the participants believed that it was 'normal' for young people to try drugs at least once and most of them experimented with cannabis and ecstasy, Bryan, A. et al., (2000). However, since the vast majority viewed the phenomenon as negative, a strong hope exist that the battle to save our children is winnable.

Furthermore, the findings revealed a highly negative and stigmatizing attitudes towards the abusers both by the community and participants which for some people can be supportive in the fight but it can equally be destructive as the more they feel ostracized and unwanted, the more they are likely not to seek support or treatments. Above all, it affects resources allocation at various levels in terms of fighting the menace. For instance, labeling them as criminals and thieves, dangerous, lazy and unproductive, aimless and good for nothing, cursed and a societal burden, disbelievers and evils, shameless and disappointing, failures, etc. does not denied them community support, push them into hiding, make them reluctant or even afraid to seek treatments, skip appointments, etc. but make their situations worse. This findings is strongly supported by local people saw cannabis users as being immature and incapable of looking after their self, Anderson, Z. (2004). Inability to share problems with others and stigma are the two major barriers in both groups as cited in Cunningham et al., (1993) as cited in Rapp, R. et al., (2006). Societal negative attitudes serve to exacerbate the plight of the drug abusers by increasing their sense of alienation, thus discouraging from seeking help for their problems (Power, 1989; Rhodes, 1990) as cited in Bryan, A. et al., (2000). The inability to share their concerns and problems out of fear of punishment from wellwishers as well as blackmailers, rejection, blame and guilt coupled with ignorance, they shun from seeking social support both from the family, friends and other authorities forced them to accept the situation as helplessness and above all making it more complex Singh, B. et al., (2017). Women addicts skip treatment 


\section{COUNS-EDU}

Vol.4, No.1, 2019

appointment or avoid treatment altogether to manage the risk of detection by health workers and justice authorities, Stone, R. (2015). However, Rapp, R. et al., (2006) found contrary, the barriers that interfere with treatment entry are a part of most substance abusers' life styles, as well as substance abusers' treatment.

The results furthermore, unearthed different types of children being engaged in drug abuse or are at the risk of it namely, school drop outs, street children, children of jobless parents, children of drug abusers, children from poor family, children of homeless parents, poor performing students, orphans, single parent children, children of divorced parents, etc. which is in agreement with youth of single parent are at high risk for drug abuse as compare to adolescent with dual parents because single parents have financial crises and have less time to monitor their children Hemovich, V. et al., (2011) cited in Somani, S. et al., (2016). Children and adolescents from economically deprived families and communities are at risk of engaging in substance abuse Spooner, et al., (2005) as cited in Morojele, N. et al., (n.d.). In the absence of nurturing home environments children and adolescents often become more inclined to seek others, who are mostly fellow peers, to fulfill their need for acceptance and recognition with greater risk of drug use Brook et al., (2006) as cited in Morojele, N. et al. (n.d.).

The causes of drug abuse among children are adults marital conflicts, limited time for socialization, being orphans, selling and consuming drugs within the confines of households, peer influence, poverty, joblessness which result into idling, (Kudrati, M. et al., 2008; Nada, K.H. et al., 2010; Morakinyo, J. et al., 2003) as quoted in Cumber, S. M., et al., (2015). Socio-economic status (e.g. living in a deprived neighborhood, low income level) is an important risk factor for problematic behaviors, including alcohol and drug abuse, Matens, M. et al., (2006) as quoted in Tulu, S. K. et al., (2015).

Although all participants subscribed to children abusing drugs, the rationales advanced were mixed. For examples, peer influence and media, pleasure and brevity seeking, poor academic achievements, unstable or broken home environment, easy affordability and living with abusers, ignorance and poverty, curiosity and weak law enforcement, easy accessibility and public acceptance, not fearing of parents and adults, lack of parental supervision; and to work or study hard for long hours, etc. The findings is supported by, numerous factors can enhance the risk for initiating or continuing substance abuse including socioeconomic status, quality of parenting skills, peer group influence, and biological/inherent predisposition towards drug addiction, National Institute on Drug Abuse, (2010) as cited in Das, J. K. et al. (2016). The major determinants of substance abuse include desires to relax or sleep after hard day's job, work hard, relieve stress; and pleasure is the major factors associated with the abuse of substances by respondents, Yunusa, U. et al., (2017). Students use alcohol and drugs believing that such stimulation activate their brains which in return helps them to study hard and overcome teaching and learning process and meet deadline Meressa, K. et al., (2009) as quoted in Tulu, S. K. et al., (2015). The motives for using alcohol include staying awake in order to study at night, to forget problems, alleviate anxiety, enjoy festival, non-existence of alcohol control policies increasing its availability; and peer pressure, Dumbili, E.W. (2015). Peer pressure and exposure to drug-related marketing activities are predisposing factors for adolescents to initiate drug abuse, Somani, S. et al., (2016). Children in The Gambia misuse illicit drugs to escape problems, such as poverty, failure in school and unemployment, Youth Front Against Drugs and Alcohol Abuse, (2004) as cited in Anderson, Z. (2004).

In addition, the study revealed different places where children mostly abuse drugs namely; peers' homes, street corners, car parks, night and video clubs, ghettoes and during parties, schools, beach sides/tourism areas, children's own homes, etc. This concurs with schools are known to be the temples of knowledge and wisdom but they do not have power to closely monitor the life activities and events of students to a check against smoking, drinking, sex or poor eating patterns and others, Singh, B. et al., (2017). Traditional illicit drugs, cocaine misuse is very high in club culture, Vento, A.E. et al., (2014). One participant initiated substance use with his mother's supply and escalated immediately to daily use by continuing to steal his mother's alcohol and prescription drugs, Kingston, S. et al., (2017). The most common place for initiation of substance abuse was recreational avenues for males and homes for females, Sarangi, L. et al., (2008). Nightlife tourism is a booming business and the levels of drug and alcohol use and associated risk taking behaviors are often increased during these nightlife holiday periods, Hughes, et al., (2011) as cited in Healthy Nightlife Toolbox - Info sheet, (2016). 
Similarly the findings revealed that children obtain drugs through various means including peers offering them, buying them jointly, adults abusers offerings them, picking remains in streets and ghettoes, stealing, as gifts for services to sellers, buying them individually, payment for services and including romantic ones, etc. This is supported the by drugs initiators often obtained substances from friends but more frequently they stole them from parents or guardians, Kingston, S. et al., (2017). A majority of the adolescents purchase substances from their self-earning, Sarangi, L. et al., (2008). Panhandling is the most common source of income for homeless adolescents; however, they also earn income through prostitution, drug distribution, stealing, trading sex for money; and from parents/other family members or friends (O'Grady, B. et al., 2004; Farrow, J.A. et al., 1992; Unger, J.B. et al., 1998) as cited in Gomez, R. et al., (2010). Sometimes, children and adolescents indulge in drug abuse are forced into sex in exchange for drugs, Singh, B. et al., (2017). Many people may become involved in the sex industry to finance their drug addiction and often trade their body for drugs, DARA, (n.d.).

\section{Level of Knowledge of the Causes of Street Children Abusing Drugs}

The findings revealed that street children like other children are engaged in drugs abuse and for numerous reasons including peer influence and group recognition, lack of parental supervision or control, curiosity and residing adult abusers, lack of stable home environment, to work hard and for long hours, to relieve stress, ignorance, easy accessibility, for seeking pleasure and relaxation, easy affordability, etc. as unearthed by street children use psychoactive substance for coping and fitting into street life circumstances, boldness to withstand violence, survival sex, pleasure, to curb hunger, to induce sleep, to numb emotions; and for entertainment (Kudrati, M. et al., 2008; Nada, K.H. et al., 2010; Morakinyo, J. et al., 2003) as quoted in Cumber, S. M., et al., (2015).

The most common reasons for substance abuse were due to peer pressure, experimentation or to boost self-confidence, Abhay, M. et al. (2007). Drug use is a feature of adolescent gangs and other marginalized peer group networks such as street children, and being a member of such groups often necessitates the use of different drugs, Bility, (1999) as cited in Morojele, N. et al. (n.d.). Factors influencing adolescent drug abuse include poor self-image, low religiosity, poor school performance, parental rejection, family dysfunction, abuse, under-or over-controlling by parents, and divorce (Block, B.J. et al., (1988); Brown, K.S.G. et al., (1983) as quoted in Shinitzky, H.M.E. et al., (1998). In the absence of nurturing home environments children and adolescents often become more inclined to seek others, who are mostly fellow peers, to fulfill their need for acceptance and recognition with greater risk of drug use, Brook et al., (2006) as cited in Morojele, N. et al. (n.d.).

Similarly, the study revealed different perceived benefits for street children abusing drugs such as hallucination or feeling high, to feel accepted and trusted by peers, drowsiness, ability to work hard and for long hours, brevity, ability to focus or concentrate, ability to think and memorize quickly, etc. This concurs with the use of drugs and alcohol gives children the necessary courage to engage in violent behaviors and to instill fear in people, Salaam, A.O. et al., (2011). A moderate positive correlation exist between intrinsic anger and addiction severity, and a negative correlation between controlled anger and addiction severity, Avci, D. et al., (2017). Children abuse drugs for numerous reasons and benefits such as curiosity and recreation to cope with stress however, it leads to complex sets of social, medical and economic problems, Sharma, N. et al., (2013). Patrick, M. E. et al., (2011), use of cannabis was significantly associated with to get high, because of boredom, to relax, because of anger or frustration, and the increase the effects of other drugs.

Myburgh, C. et al., (2015), street children are constantly threatened, exploited and exposed to physical, sexual and emotional abuse on a daily by the community, the authorities and other street dwellers; and this leads to feelings of sadness, fear, anxiety, misery, despair, hopelessness, helplessness and suicide ideation, which in turn lead to drug abuse and criminal activities to cope with the associated anxiety.

\section{Level of Knowledge of Negative Impacts of Drug Abuse}

The findings indicate participants' strong awareness of the negative impacts of street children engagement in drug abuse. For instance, mental illness, aggressive conduct/behavior, frequent problems and beating by others at work places, endless problems with peers, frequent stealing and fighting, hatred towards school and formal education, endless family problems, diseases (e.g. HIV/AIDS, TB, STIs, etc.), road accidents involvement, stroke, etc. These revelations support street children are exposed to an 
assortment of risks to resilience that characterize their lives such as drug abuse, violence, gangs, HIV infection, illiteracy, incomplete schooling, delinquency, neglect, poor health and nutrition Montane, (2006) as cited in Molahlehi, L. A. (2014). Substance abuse leads to road crashes, conduct problems, attentional problems, suicide, homicide, a range of injuries, poisoning; and spread of infectious diseases (Fergusson, D.M. 2007; Toumbourou, J.W. et al., 2007) as cited in Lucchetti, G. et al. (2014). The effects of drug abuse among children are coughing and chest pains, self-denial, societal denial, loss of weight, early pregnancies, prostitution, mental illness, harassment by police force, school dropout; and HIV/AIDS infection, Matowo, A. S. (2013). Absenteeism, school dropouts, poor performance, aggressive behavior, bullying, fighting, suppressed anger, criticism, isolation, rejection, cheating, stealing, lying, truancy, low self-esteem, loneliness, guilt, feeling of helplessness, fear of abandonment, and chronic depression manipulating become the usual defensive behaviors of drug abusers both in school and at home, Millar, et al., (2000) as cited in Singh, B. et al., (2017). Alcohol and drug abuse causes delinquent behaviors including unsafe sexual practice, gangs, drug trafficking, prostitution, physical, sexual abuse; and growing number of youth murders (Wechler, H.M. et al., 2004; Gezanhegn, T. et al., 2014; Didenko, et al., 2007) as quoted in Tulu, S. K. et al., (2015).

Similarly, the findings revealed the following drugs; marijuana, inhalant, alcohol, antibiotics, opium, diazepam, hashish, heroin, cocaine and paracetamol, etc. being among the most commonly abuse drugs by street children concurring with studies from Nigeria, India and Brazil that revealed the most commonly abuse substances include alcohol, kolanut, tobacco, cannabis, nicotine, inhalants; and marijuana (Morakinyo, J. et al. (2003); Pagare, D. et al., (2004); Praveen, D. et al., (2014) as cited in (94. Islam, F. et al., (2014). Rao, (2010) as cited in Singh, B. et al., (2017), the most common substance consumed was nicotine, as cigarettes and inhalants/volatile substance used in the form of sniffing of adhesive glue, petrol, gasoline, thinner, and spirit. Yunusa, U. et al., (2017), the most commonly abused substances by commercial drivers include solution, coffee, tramadol, local stimulant tea, cola-nut and tobacco. Gilvarry, E. (2000), cannabis is the most widely misused illicit substance by the Western youth. Drug Law Enforcement Agency the Gambia (DLEAG) (2017), in The Gambia, while there is a presence of other hard drugs like cocaine, heroin, clonazepam, diazepam, bronazepam; marijuana is the most commonly abuse illicit drug simply because of its affordability, availability and accessibility as it is grow locally and easily trafficked from the Cassamance region in Senegal

\section{Level of Knowledge of the Preventive Methods of Drug Abuse}

The results indicate that participants have a good knowledge of some of the critical methods in the fight against drug abuse such as, avoidance of bad peer groups, regular education and/or sensitization campaign, closeness to responsible adults, mainstreaming drug abuse in school curriculum, engagement in self-esteem building activities, provision of gainful employments and family support, engagement in productive activities, effective law enforcement agencies, good parenting skills, tough laws, storing drugs safely, etc. This is in agreement with social bond and attachment with parents can decrease the consumption of drug among youth Aliiaskarov, B. et al., (2013) cited in Somani, S. et al., (2016). Increased child monitoring is associated with a decreased risk of alcohol and other drugs (Amoaten et al., 2004) as cited in Morojele, N. et al. (n.d.). In the campaign of reducing substance abuse in adolescents, the media needs to be involved from the start till the end of the campaign as they need to telecast talk shows, announcements related to the programs, conferences, story making, newspaper article coverage and commercials to prohibit substance use among youth, Somani, S. et al., (2016). Preventive programmes for high school students should increase academic and social competence with the following skills: study habits, communication, peer relationships; self-efficacy and assertiveness, drug resistance skills, reinforcement of antidrug attitudes; strengthening of personal commitment against drug abuse (Botvin et al., 1995; Scheier et al., 1999) as quoted in National Institute on Drugs, (2003). Various platforms including school and family programmes, the mass media including the digital ones, and public policy have the potential to improve and prevent substance abuse among adolescents, Das, J. K. et al. (2016). Prevention programmes for school children should focus on developing and strengthening the following skills: self-control, emotional awareness, communication, social problem solving, reading and understanding, peer relationship, self-efficacy and assertiveness, drug resistance, reinforcement of antidrug attitudes; and commitments against drug abuse (Ialongo et al., 2001) as cited in National Institute on Drugs, (2003). Alhyas, L. et al., (2015), multifactorial prevention programmes that address social norms, gender role image, and incorporate drug policy, religion, family and school would be more effective and would have better protective outcomes. 
Similarly, regular sensitization and/or education campaigns, avoidance of bad peer group, development of strong personalities and resistant skills, self-esteem building techniques, strengthening of family support programmes, promotion of strong parent-child relationship, regular monitoring of children's activities and ensuring open line communication with children, regular engagement in useful activities, all the time closeness to responsible adults and religious persons, mainstreaming drug abuse in school curriculum, frequent one-on-one discussions, good parenting skills, provision of gainful employments for families, etc. were recognized as the most effective ways of preventing drug abuse among children. This concur with Guillen, et al.,(2015) as quoted in Singh, B. et al., (2017), parental monitoring would be able to strengthen resistance to peer pressure and therefore it can be expected to reduce substance abuse. Plummer et al., (2007) as quoted in Molahlehi, L. A. (2014), maintain that child welfare agencies should take steps in order to prevent the problem through the creation of preventive educational programmes for working with these children. Substance abuse can be reduced by controlling the production and sale of commonly abused substance, Yunusa, U. et al., (2017).

Subjective adults' norms against drug use and community affirmation of positive behavior have been found to be related to less smoking behavior among young people, King et al., 2003) as cited in Morojele, N. et al. (n.d.). Governments in collaboration with NGOs should create employment opportunities to the people, established enough rehabilitation and correction centers, schools, health facilities, more campaigns for the rights of street children rights, commemorate "street children's Day" (31st January) and empower street children by providing outreach education, training, food and health services, Poni-Gore, et al. (2015). Greater religious involvement is associated with less alcohol use and drunkenness (Parry et al., 2004a) as cited in Morojele, N. et al. (n.d.).

\section{Level of Knowledge of the Support Services and Treatments Needed by Drug Abusers}

The results revealed high level of awareness of the support services and treatments needed by victims of drugs of abuse such as providing them with behavioral counseling or therapy, support groups including spiritual ones, supportive friends and family environment, a sober living environment, regular family support, a sober social network and/or peers, regular and affordable medical treatments, uninterrupted educational services, traditional or herbal treatments, vocational training or skills, etc. concurring with social support has been associated with better quality of life both among substance users and individuals with mental disorders and equally a significant correlate of subjective well-being among recovering substance users who are dually-diagnosed with comorbid psychiatric disorder (Brennan et al., 1990; Nelson, 1992; Laudet et al., 2000) as quoted in Laudet, A. B. et al., (2006). Living in sober houses is beneficial and effective in assisting the reduction of substance use (Polcin, D.L. et al., (2010); Jason, L.A. (2007) as cited in Tulu, k. et al., (2016). Treatment works with the support of the family and the community, therefore empowering the community to mobilize around alcohol and related issues can be a powerful strategy (Rataemane, 2004) as cited in Setlalentoa, M. et al., (2015). Stevens, E. et al., (2015), a significant positive relationship exists between general social support and abstinence and self-efficacy. Religion does not only encourage abstinence but rebuild life through new networks, ways of spending free time by doing voluntary works, group cohesion, unconditional support and the establishment of new family, Sanchez, V. D. M. et al., (2008). Incorporation of the clients' spiritual themes into treatment can significantly increase the efficacy of cognitive therapy for depression Propst et al., (1992) as cited in Allamani, A. (2010).

Furthermore, the findings revealed the government institutions, local government authorities, United Nations agencies, support groups, mosques/marabous/churches, community based organizations (CBO), the community, the family, Non-Governmental Organization, faith based organizations (FBO), etc. as the fundamental providers of these services and treatments which strongly allied to a collaborative approach to engage the community in addressing substance abuse, Windsor, L.C. et al., (2012). Kelly, S. M. et al., (2010), individuals who were in treatment, as compared with those who were out of treatment, perceived significantly greater support from their partners or family with whom they lived, family members outside the home, friends, and their communities at treatment entry.

However, majority claimed the support do not exist in their society concurring with Naamara, W. et al., (2014), there is a lack of rehabilitation services in local communities and alcohol problems are usually ignored "People who are alcohol dependent in my community do not have services to help them. It is when someone dies of alcohol related problems that people start saying that alcohol is bad." 


\section{COUNS-EDU}

Vol.4, No.1, 2019

Concluded a respondent. Sodano, R. et al., (2010), the substance abuse treatment workforce of South Africa appears to be young and educated, yet only one third of the counselors had any formal training in Cognitive Behavioral Therapy. Liranso G. et al. (2017), drug addiction and mental health treatment is limited in the region, and therefore the phenomena are poorly understood and lack attention. Myers, B. et al., (2008), identified three structural barriers to service delivery (i)difficulty in developing and implementing a strategic plan relating to alcohol and drug problems due to poor capacity and other structural issues, such as a lack of information, poor intersectoral collaboration and limited consultation and limited providers; (ii)limited allocation of resources to alcohol and drug treatment which has restricted the availability of affordable services as well as the capacity of established services to meet increased demand for services in this area; and (iii) fragmented service delivery. Scott, C. K. et al., (2011), there is a need for more aggressive screening, early intervention, adequate initial treatment, ongoing monitoring, disease management skills, and better linkage to recovery support services and mutual aid groups that help sustain recovery.

The results indicated that the street children do not seek these support services and treatments due to fear of societal stigma and discrimination, they don't want people to know them, fear of rejection by peers, the services providers are not child friendly, fear of being reported to the security agencies, the supports are expensive, they don't trust the service providers, the services are not effective, they are not easily accessible, etc. which concurs with inability to share problems with others and stigma are the two major barriers in both groups as cited in Cunningham et al., (1993) as cited in Rapp, R. et al., (2006). Tucker et al., (2004) as cited in Rapp, R. et al., (2006), found three areas of importance privacy, participants' belief that treatment was unnecessary or not beneficial; and practical and economical impediments to participation. Sereta, B. N. et al., (2016), rehabilitation centers staff should gain insights on various needs of the rehabilitees to avert unnecessary strife in the rehabilitees and as such they should learn to handle the rehabilitees with professionalism to enable a successful rehabilitation process. Grant, (1997) as quoted in Rapp, R. et al., (2006), their lack of confidence in the effectiveness of alcoholism treatment, stigmatization, and denial as conditions that would interfere with linkage. National Institute on Drugs, (2003), service providers that identify, understand, and facilitate social processes that reduce harm without judgment or condemnation will likely find greater success in assisting these young people. Kalebka, R.R. et al., (2013), although the willingness to initiate therapeutic measures in the emergency centers exist, more training in this field may beneficial. However, Rapp, R. et al., (2006), found some barriers that interfere with treatment entry are a part of most substance abusers' life styles, as well as substance abusers' treatment.

Furthermore, finding revealed street children including commercial vans casual apprentices like other children are abusing drugs mainly due to peer influence, seeking pleasure and relaxation, to work hard and for long hours, curiosity, ignorance, easy accessibility and Lack of or inadequate stable home environment, lack of or poor parental supervision, easy affordability, etc. This concurs with Boys, A. et al., (2001), the most popular function for drug use to relax, become intoxicated, keep awake at night while socializing, enhance an activity and alleviate depress mood. Cumber, S.N. et al., (2015), street children use psychoactive substance for coping and fitting into street life circumstances, boldness to withstand violence, survival sex, pleasure, to curb hunger, to induce sleep, to numb emotions; and for entertainment.

Morojele, N. et al. (n.d.), although current legislation prohibits the sale of alcohol to people under the age of 18 years, it is relatively easy for them to access alcohol either directly or indirectly, since laws are not enforced consistently. Bereavement in families and relationship difficulties, poor relationship between children and parents leads to increase alcohol consumption and also parents abusing drugs are causative factors (Khan, M.H. et al., 2004; Aliiaskarov, B. et al., 2013; Niaz, U. et al., 2005) cited in Somani, S. et al., (2016). Psychological distress, including low self-esteem and depression, contribute to the initiation and maintenance of drug use (Gezanhegn, T. et al., 2014) as quoted in Tulu, S. K. et al., (2015).

\section{Conclusions}

To comprehend the vulnerability of street children to drug abuse six main areas were explored namely, level of knowledge of drug abuse, perception towards it, level of knowledge of the causes of it in 
the community and among street children, level of knowledge of the negative impacts of it, level of knowledge of the preventive methods; and level of knowledge of the support services and treatments needed by victims. The findings revealed among other things, that there is high level of consciousness of drug abuse but the feelings towards it is mixed. Like other children, street children are abusing drugs mainly due to peer influence with the ultimate objective of getting high to relief stress, group recognition, trusted by peers, etc. Similarly, participants are highly aware of the negative impacts encompassing fighting, stealing, mental illness, etc. To finance the behaviour, victims are engaged in all types of dangerous antisocial behaviour including romantic ones exposing them to a range of diseases including STIs. While participants have good knowledge of the critical methods to fight drug abuse, the support services needed by victims, victims are mostly reluctant to seek the services not only because they are hard to find but fear societal stigmatization, exclusion, discrimination; and professionals' maltreatment. Though in the minority some children have started abusing hard drugs. In conclusion, some children including street children are abusing drugs and urgent actions need to be taken to rehabilitate and protect the future of the country.

\section{References}

Adebiyi, A. O., Owoaje, O., \& Asuzu, M. C. (2008). Relationships as determinants of substance use amongst street children in a local. South African Family Practice, 50(5), 47-47.

Alhyas, L., Al Ozaibi, N., Elarabi, H., El-Kashef, A., Wanigaratne, S., Almarzouqi, A., ... \& Al Ghaferi, H. (2015). Adolescents' perception of substance use and factors influencing its use: a qualitative study in Abu Dhabi. JRSM open, 6(2), 2054270414567167.

Aliiaskarov, B., \& Bakiev, E. (2014). The social learning and social control determinants of alcohol use among youth in Kyrgyzstan. Drugs: education, prevention and policy, 21(3), 205-210.

Allamani, A. (2010). The relationship between addiction and religion and its possible implication for care.

Anderson, Z. (2004). An investigation into the problems associated with substance use in a developing country-The Gambia, West Africa. Centre for Public Health, Liverpool John Moores University.

Antwi, J. D., Adjei, S., Asare, J. B., \& Twene, R. (2003). A national survey o n prevalence and social consequences of substance (drug) use among secon d cycle and out of school youth in Ghana. Ministry of Health/Ghana Health Service. WHO Ghana.

Belcher, H. M., \& Shinitzky, H. E. (1998). Substance abuse in children: Prediction, protection, and prevention. Archives of pediatrics \& adolescent medicine, 152(10), 952-960.

Blas, E., \& Kurup, A. S. (Eds.). (2010). Equity, social determinants and public health programmes. World Health Organization.

Boys, A., Marsden, J., \& Strang, J. (2001). Understanding reasons for drug use amongst young people: a functional perspective. Health education research, 16(4), 457-469.

Bryan, A., Moran, R., Farrell, E., \& O'Brien, M. (2000). Drug-related knowledge, attitudes and beliefs in Ireland: report of a nation-wide survey. Drug Misuse Research Division, Health Research Board.

Bühler, A., Schröder, E., \& Silbereisen, R. K. (2007). The role of life skills promotion in substance abuse prevention: a mediation analysis. Health education research, 23(4), 621-632.

Chie, Q. T., Tam, C. L., Bonn, G., Wong, C. P., Dang, H. M., \& Khairuddin, R. (2015). Drug abuse, relapse, and prevention education in Malaysia: perspective of university students through a mixed methods approach. Frontiers in psychiatry, 6, 65

Cumber, S. N., \& Tsoka-Gwegweni, J. M. (2015). The health profile of street children in Africa: a literature review. Journal of public health in Africa, 6(2).

DARA, (n.d.). Thailand Drug and Alcohol Rehab in Thailand. Retrieved from http://alcoholrehab.com/drug-addiction/sexual-exploitation-and-substance-abuse/

Das, J. K., Salam, R. A., Arshad, A., Finkelstein, Y., \& Bhutta, Z. A. (2016). Interventions for adolescent substance abuse: An overview of systematic reviews. Journal of Adolescent Health, 59(4), S61-S75.

Drug Law Enforcement Agency the Gambia (DLEAG) (2017). Drug Abuse Situation in The Gambia. Retrieved from http://www.dleag-gambia.org/en/article/drug-abuse-situation-gambia

Dumbili, E. W. (2015). A review of substance use among secondary school students in Nigeria: Implications for policies. Drugs: Education, Prevention and Policy, 22(5), 387-399. 
DW Made for Mind (2013). Illegal drug use on the rise in Africa. Retrieved from http://www.dw.com/en/illegal-drug-use-on-the-rise-in-africa/a-16614023

Embleton, L., Mwangi, A., Vreeman, R., Ayuku, D., \& Braitstein, P. (2013). The epidemiology of substance use among street children in resource-constrained settings: a systematic review and meta-analysis. Addiction, 108(10), 1722-1733

Faria Filho, E. A., Queiros, P. S., Medeiros, M., Rosso, C. F. W., \& Souza, M. M. D. (2015). Perceptions of adolescent students about drugs. Revista brasileira de enfermagem, 68(3), 517-523.

Gaidhane, A. M., Syed Zahiruddin, Q., Waghmare, L., Shanbhag, S., Zodpey, S., \& Joharapurkar, S. R. (2008). Substance abuse among street children in Mumbai. Vulnerable Children and Youth Studies, $3(1), 42-51$.

Gilvarry, E. (2000). Substance abuse in young people. The Journal of Child Psychology and Psychiatry and Allied Disciplines, 41(1), 55-80.

Gomez, R., Thompson, S. J., \& Barczyk, A. N. (2010). Factors associated with substance use among homeless young adults. Substance Abuse, 31(1), 24-34.

Gossop, M., Stephens, S., Stewart, D., Marshall, J., Bearn, J., \& Strang, J. (2001). Health care professionals referred for treatment of alcohol and drug problems. Alcohol and Alcoholism, 36(2), 160164.

Healthy Nightlife Toolbox - Info sheet, (2016). Responding to drug and alcohol use and related problems in nightlife settings. Retrieved from http://www.hntinfo.eu/sites/hntinfo.eu/files/AF1454Infosheet_April_2016def_Web.pdf

Heckman, C. J., Dykstra, J. L., \& Collins, B. N. (2011). Substance-related knowledge, attitude, and behaviour among college students: Opportunities for health education. Health education journal, 70(4), 383-399.

Hemovich, V., Lac, A., \& Crano, W. D. (2011). Understanding early-onset drug and alcohol outcomes among youth: The role of family structure, social factors, and interpersonal perceptions of use. Psychology, health \& medicine, 16(3), 249-267.

Integrated Regional Information Networks (IRIN) (2009). Street children persist despite crackdown. Retrieved from http://www.irinnews.org/report/84713/gambia-street-children-persist-despitecrackdown

Islam, F., Kar, S., Debroy, A., \& Sarma, R. (2014). Substance abuse amongst the street children in Guwahati city, Assam. Annals of medical and health sciences research, 4(3), 233-238.

Kalebka, R. R., Bruijns, S. R., \& Van Hoving, D. J. (2013). A survey of attitudes towards patient substance abuse and addiction in the Emergency Centre. African Journal of Emergency Medicine, 3(1), $10-17$.

Kelly, S. M., O'Grady, K. E., Schwartz, R. P., Peterson, J. A., Wilson, M. E., \& Brown, B. S. (2010). The relationship of social support to treatment entry and engagement: The Community Assessment Inventory. Substance abuse, 31(1), 43-52.

Kingston, S., Rose, M., Cohen-Serrins, J., \& Knight, E. (2017). A qualitative study of the context of child and adolescent substance use initiation and patterns of use in the first year for early and later initiators. PLoS one, 12(1), e0170794.

Laudet, A. B., Morgen, K., \& White, W. L. (2006). The role of social supports, spirituality, religiousness, life meaning and affiliation with 12-step fellowships in quality of life satisfaction among individuals in recovery from alcohol and drug problems. Alcoholism treatment quarterly, 24(1-2), 33-73.

Liranso G. et al. (2017). Drug Addiction and Mental Illness Treatment in Sub Saharan Africa. Retrieved from https://www.jscimedcentral.com/SubstanceAbuse/substanceabuse-5-1064.pdf

Low, W. Y., Zulkifil, S. N., Yusof, K., Batumalai, S., \& Aye, K. W. (1995). Knowledge, Attitudes and Perceptions Related to Drug Abuse In Peninsula Malaysia: A Survey Report. Asia Pacific Journal of Public Health, 8(2), 123-129.

Lucchetti, G., \& Granero Lucchetti, A. L. (2014). Spirituality, religiosity and substance use: evidence and proposed mechanisms. J Subst Abuse Alcohol, 2(2), 1016.

Madde, Ç. E. D. E. E. (2017). Prevalence of Substance Use among Adolescents Participating in Apprenticeship Training and the Relationship Between Anger Level-Anger Expression and Addiction Severity. Journal of Psychiatric Nursing, 8(1), 1-8.

Majelantle, R. G., Keetile, M., Bainame, K., \& Nkawana, P. (2014). Knowledge, Opinions and attitudes towards HIV and AIDS among Youth in Botswana. Journal of Global Economics. 
Mamat, C. F., Jamshed, S. Q., El Syed, T., Khan, T. M., Othman, N., Al-Shami, A. K., ... \& Siddiqui, M. J. (2015). The use of psychotropic substances among students: The prevalence, factor association, and abuse. Journal of pharmacy \& bioallied sciences, 7(3), 181.

Matowo, A. S. (2013). Cause, Effect and Remedial Measures of Drug Abuse Among the Children in Tanzania: A Case Study of Hananasifu Ward in Kinondoni District in Dar Es Salaam Region.

Molahlehi, L. A. (2014). The views of street children on how streetism can be prevented (Doctoral dissertation, North West University).

Mondal, N. K. (2013). Commercial Glue Sniffing and Child Health: Indian Street Children are at a Risk. J Biosafety Health Educ, 1(3).

Morojele, N. et al., (n.d.).Alcohol and Drug Use. Retrieved from http://citeseerx.ist.psu.edu/viewdoc/download?doi=10.1.1.717.3977\&rep=rep1\&type=pdf

Myburgh, C., Moolla, A., \& Poggenpoel, M. (2015). The lived experiences of children living on the streets of Hillbrow. curationis, 38(1), 1-8.

Myers, B., Louw, J., \& Fakier, N. (2008). Alcohol and drug abuse: removing structural barriers to treatment for historically disadvantaged communities in Cape Town. International Journal of Social Welfare, $17(2), 156-165$

Naamara, W., \& Muhwezi, W. W. (2014). Factors associated with alcohol dependence among adult male clients in Butabika Hospital, Uganda. Journal of social work practice in the addictions, 14(3), 322-326.

National Institute on Drugs, (2003). Preventing Drug Use among Children and Adolescents. Retrieved from https://www.drugabuse.gov/sites/default/files/preventingdruguse_2.pdf

Niazi, M.R. et al., (2009). Is Poverty to Blame for Narcotic Abuse: Case Study of Pakistan? Retrieved from http://www.ijens.org/99610-1212\%20IJBAS-IJENS.pdf

Patrick, M. E., Schulenberg, J. E., O'malley, P. M., Johnston, L. D., \& Bachman, J. G. (2011). Adolescents' reported reasons for alcohol and marijuana use as predictors of substance use and problems in adulthood. Journal of studies on alcohol and drugs, 72(1), 106-116.

Peltzer, K., Ramlagan, S., Johnson, B. D., \& Phaswana-Mafuya, N. (2010). Illicit drug use and treatment in South Africa: a review. Substance use \& misuse, 45(13), 2221-2243.

Poni-Gore, R., Loro, R. L., Oryem, E., Iro, R. E., \& Reec, W. B. (2015). Phenomena of street children life in Juba, the capital of South Sudan, a problem attributed to long civil war in Sudan. Journal of Community Medicine. Retrieved from http://dx. doi. org/10.4172/2161-0711.1000356.

Rambaree, K., Mousavi, F., \& Ahmadi, F. (2018). Sports participation and drug use among young people in Mauritius. International Journal of Adolescence and Youth, 23(2), 188-197.

Rapp, R. C., Xu, J., Carr, C. A., Lane, D. T., Wang, J., \& Carlson, R. (2006). Treatment barriers identified by substance abusers assessed at a centralized intake unit. Journal of substance abuse treatment, 30(3), 227-235

Salaam, A. O. (2011). Street Life Involvement and Substance Use Among "Yandaba" In Kano, Nigeria. African Journal of Drug and Alcohol Studies, 10(2)

Sampasa-Kanyinga, H., Hamilton, H. A., LeBlanc, A. G., \& Chaput, J. P. (2018). Cannabis use among middle and high school students in Ontario: a school-based cross-sectional study. CMAJ open, 6(1), E50.

Sanchez, Z. V. D. M., \& Nappo, S. A. (2008). Religious intervention and recovery from drug addiction. Revista de saude publica, 42(2), 265-272.

Sarangi, L., Acharya, H. P., \& Panigrahi, O. P. (2008). Substance abuse among adolescents in urban slums of Sambalpur. Indian journal of community medicine: official publication of Indian Association of Preventive \& Social Medicine, 33(4), 265.

Schensul, J. J., \& Burkholder, G. J. (2005). Vulnerability, social networks, sites, and selling as predictors of drug use among urban African American and Puerto Rican emerging adults. Journal of Drug Issues, 35(2), 379-408.

Scott, C. K., Dennis, M. L., Laudet, A., Funk, R. R., \& Simeone, R. S. (2011). Surviving drug addiction: the effect of treatment and abstinence on mortality. American Journal of Public Health, 101(4), 737744.

Sereta, B. N., Amimo, F. A., Ouma, P., \& Ondimu, T. O. (2016). An Assessment of Effectiveness of Drug Rehabilitation Programs in Kisii County-Kenya. J Health Edu Res Dev, 4(165), 2

Setlalentoa, M., Ryke, E., \& Strydom, H. (2015). Intervention strategies used to address alcohol abuse in the North West province, South Africa. Social Work, 51(1), 80-100. 
Sharma, N., \& Joshi, S. (2013). Preventing-substance abuse among street children in India: a literature review. Health Science Journal, 7(2).

Singh, B. et al., (2017). Substance Abuse among Children: A Rising Problem in India. Retrieved from http://www.ijip.in/Archive/v5i1/18.01.020.20170501.pdf

Sodano, R., Watson, D. W., Rataemane, S., Rataemane, L., Ntlhe, N., \& Rawson, R. (2010). The substance abuse treatment workforce of South Africa. International journal of mental health and addiction, 8(4), 608-615.

Somani, S., \& Meghani, S. (2016). Substance Abuse among Youth: A Harsh Reality. Emerg Med (Los Angel), 6(330), 2.

Sorsdahl, K., Stein, D. J., \& Myers, B. (2012). Negative attributions towards people with substance use disorders in South Africa: Variation across substances and by gender. BMC psychiatry, 12(1), 101

Stevens, E., Jason, L. A., Ram, D., \& Light, J. (2015). Investigating social support and network relationships in substance use disorder recovery. Substance abuse, 36(4), 396-399.

Stone, R. (2015). Pregnant women and substance use: fear, stigma, and barriers to care. Health \& Justice, $3(1), 2$.

The Real Truth (n.d.). Drug Abuse-A Global Epidemic Part 2: Scope of the Problem. Retrieved from https://rcg.org/realtruth/articles/120712-004.html

Tracy, K., \& Wallace, S. P. (2016). Benefits of peer support groups in the treatment of addiction. Substance abuse and rehabilitation, 7, 143 .

Tulu, S. K., \& Keskis, W. (2015). Assessment of causes, prevalence and consequences of alcohol and drug abuse among Mekelle University, CSSL 2nd year students. American Journal of Applied Psychology,(3), $3,47-56$.

UN News (2016). Record 29 million people drug-dependent worldwide; heroin use up sharply -UN report. Retrieved from https://news.un.org/en/story/2016/06/532862-record-29-million-people-drugdependent-worldwide-heroin-use-sharply-un-report

United Nations Office on Drugs and Crime (UNODC) (n.d.). World Drug Report 2017. Retrieved from https://www.unodc.org/unodc/en/press/releases/2017/June/world-drug-report-2017_-29-5million-people-globally-suffer-from-drug-use-disorders--opioids-the-most-harmful.html

Vento, A. E., Martinotti, G., Cinosi, E., Lupi, M., Acciavatti, T., Carrus, D., ... \& Corazza, O. (2014). Substance use in the club scene of Rome: a pilot study. BioMed research international, 2014.

Whitesell, M., Bachand, A., Peel, J., \& Brown, M. (2013). Familial, social, and individual factors contributing to risk for adolescent substance use. Journal of addiction, 2013, 579310-579310.

Windsor, L. C., \& Murugan, V. (2012). From the individual to the community: Perspectives about substance abuse services. Journal of social work practice in the addictions, 12(4), 412-433

Woan, J., Lin, J., \& Auerswald, C. (2013). The health status of street children and youth in low-and middle-income countries: a systematic review of the literature. Journal of Adolescent Health, 53(3), 314-321.

Yunusa, U., Bello, U. L., Idris, M., Haddad, M. M., \& Adamu, D. (2017). Determinants of Substance Abuse among Commercial Bus Drivers in Kano Metropolis, Kano State, Nigeria. American Journal of Nursing Science, 6(2), 125-130. 